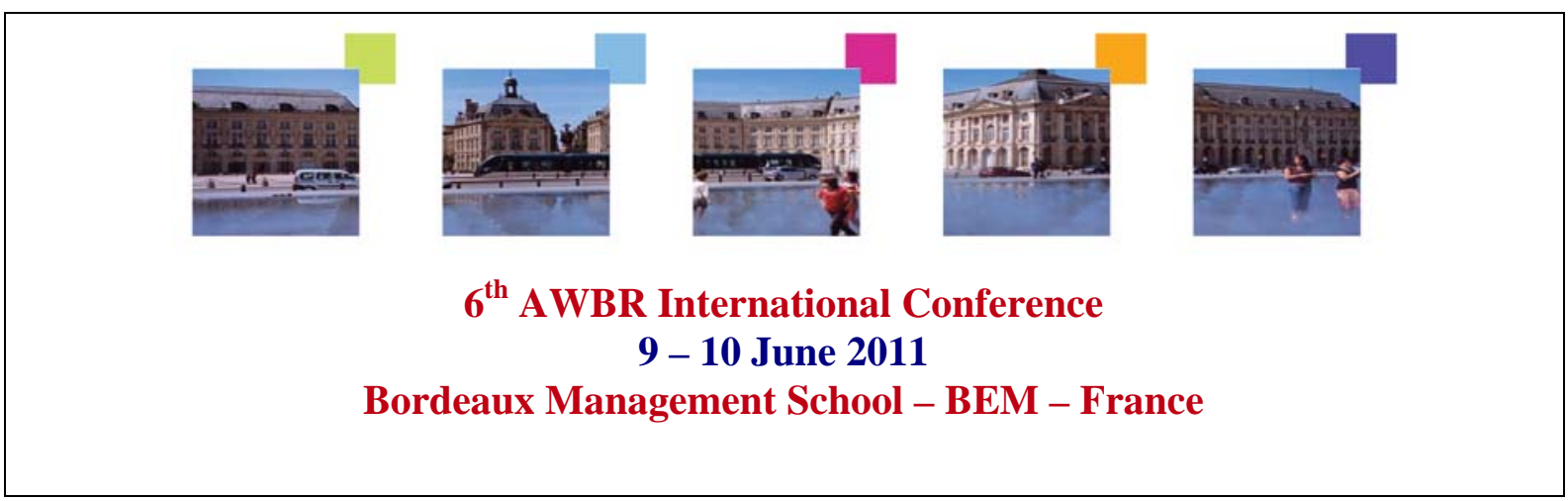

\title{
Analysis of Environmental Management Systems in New Zealand Wineries
}

\author{
Sharon L. Forbes \\ Lincoln University, New Zealand \\ (sharon.forbes@lincoln.ac.nz) \\ Tracy-Anne De Silva \\ Lincoln University, New Zealand \\ (tracy-anne.desilva@lincoln.ac.nz)
}

\begin{abstract}
-Purpose: This paper discusses the use of formal environmental management systems (EMSs) in wineries. It reports on the utilisation of EMSs amongst New Zealand wineries and explores the environmental, social and economic benefits gained through the implementation of one or more EMSs.

-Design/methodology/approach: Wineries which had implemented the Sustainable Winegrowing New Zealand (SWNZ) programme were surveyed in order to evaluate their environmental performance and the benefits received from implementing SWNZ and any additional EMSs.

-Findings: Almost half of the responding SWNZ wineries had also implemented additional EMSs, suggesting that a single EMS may not be sufficient to meet all environmental or sustainability needs. In addition, the findings suggest that wineries with multiple EMSs have better environmental performance than wineries with a single EMS, and few nonenvironmental benefits are gained by implementing an EMS.
\end{abstract}

Key words: environmental management systems, wineries, SWNZ 


\section{INTRODUCTION}

The environmental performance of the wine industry does not receive as much attention and media coverage as some other industries. Nevertheless, environmental issues relating to wine production have gained prominence in recent years. The most serious of these environmental issues include reducing the use of chemical pesticides and herbicides, reducing the loss of natural habitats and species, conserving water supply and water quality, reducing greenhouse gas emissions, reducing organic waste and packaging materials (Broome and Warner, 2008; Gabzdylova et al., 2009; Marshall et al., 2005; Musee et al., 2007; Ruggieri et al., 2009).

In response to increasing concerns from consumers, government, retailers and other stakeholders, national and regional wine industry associations around the globe have developed and promoted various environmental management systems (EMSs) or sustainability systems, based around the notion of the 'triple bottom line' to their members. The systems typically foster improved environmental health, with some also having a focus on increased social responsibility and economic viability (Zoecklein, 2010). Potoski and Prakash (2005) reported that ISO 14001 is the most widely implemented voluntary environmental program in the world. However, a vast number of alternative formal environmental management systems also exist, some of which are industry specific. This paper is particularly focused on formal EMSs which have been implemented by wineries. In recent years New Zealand Winegrowers, the national industry association, has encouraged wineries and grape growers to implement a formal industry-specific EMS which they have developed and named Sustainable Winegrowing New Zealand (SWNZ).

Whilst there is considerable literature examining consumer views of environmentally friendly products and the drivers which are encouraging companies to implement an EMS (e.g. Barber et al., 2009; Forbes et al., 2009; Gabzdylova et al., 2009; Hughey et al., 2005; Warner, 2007), prior research has seldom sought to understand the environmental, social and economic impact on a company from implementing an EMS. The authors are not aware of any prior research that has considered whether the implementation of multiple EMSs improves environmental performance to a greater extent than implementation of a single EMS. Examining the aforementioned gap is one of this study's key research questions. This study examines the extent to which the voluntary implementation of an EMS results in tangible environmental, social and economic benefits for wine companies and it also seeks to identify the effectiveness of the SWNZ programme by examining the effects on environmental performance of multiple EMSs in New Zealand wineries. In doing so, this paper contributes to the debate on the impact of EMSs on environmental and organisational performance.

This paper begins with a discussion of EMSs in general, followed by a more focused review on the use, benefits and costs of EMSs in the wine industry. The paper then outlines the method used and provides a discussion on the results and conclusions of this study.

\section{ENVIRONMENTAL MANAGEMENT SYSTEMS}

In recent years many businesses around the globe have implemented formal EMSs. An EMS has been described as a strategic management approach that defines how an organisation will address its impacts on the natural environment (Darnall et al., 2008). Similarly, Melnyk, Sroufe and Calantone (2003) stated that an EMS involves a formal system and database which integrates procedures and processes for the training of personnel, monitoring, summarising and reporting of environmental performance information to the stakeholders of 
an organisation. In general, an EMS involves the establishment of an environmental plan, the creation of goals to reduce environmental impacts, the implementation of appropriate actions, and some form of internal assessment or monitoring. The major aim of an EMS is to develop, implement, manage, coordinate and monitor environmental activities across an organisation. The assumed benefits associated with EMSs are a key driver for the increasing voluntary implementation of these environmental instruments by organisations around the globe.

Prior research has suggested that the implementation of EMSs can provide several economic and non-economic benefits for organisations (Potoski and Prakash, 2005). Indeed, Melnyk, Sroufe and Calantone (2003) stated that an EMS plays a critical role in terms of improvement to an organisation's environmental performance and also to its overall performance. The benefits that can be gained through implementation of an EMS may include improved regulatory compliance, decreased waste materials, reduced pollution emissions, enhanced corporate image, improved production efficiencies, increased customer satisfaction, access to new markets, and increased profits (e.g. Darnall et al., 2008; Potoski and Prakash, 2005; Stapleton et al., 2001). The literature provides some evidence to support the view that EMS implementation can provide benefits to an organisation. Specifically, Potoski and Prakash (2005) reported that, after examining over 3000 US companies, those who had implemented ISO 14001 had lowered their pollution emissions and thus had improved their overall environmental performance. US companies also reported significant advantages when implementing a formal certified EMS including reduced overall costs, reduced lead times, improved position in the marketplace, enhanced company reputation, better product design/development, and improved opportunities for selling products in international markets (Melnyk et al., 2003). Overall, the benefits of EMS implementation were found to significantly outweigh the costs incurred.

Additional benefits of implementing EMSs such as a heightened awareness of environmental issues among employees, a shared vision for addressing these issues, and associated increases in employee morale have also been identified (Andrews et al., 1999). In an extensive review of prior European studies, Hillary (2004) reported that organisations which had implemented a formal EMS gained internal organisational, financial and stakeholder benefits, as well as external commercial, environmental and communication benefits. The internal benefits included improved quality of management, training, and environmental information; cost savings from improved material, energy and waste efficiencies; and increased employee motivation, morale and skills. External benefits included gaining new customers or a competitive advantage, staying in businesses, assured legal compliance, increased energy efficiencies and recycling, reduced pollution, a more positive public image, better customer relationships, and improved co-operation and communication with stakeholders.

While it is clear that implementing an EMS has benefits for an organisation, companies with an EMS do not always achieve significantly better environmental performance than those without an EMS (e.g. Barla, 2007; Boiral, 2007; Hertin et al., 2008; Nawrocka and Parker, 2009). These results suggest that EMSs do not always achieve their basic aim of improving environmental performance. Prior research also provides evidence of other disbenefits associated with EMS implementation. Welch, Rana and Mori (2003) reported that for most of the nearly 2,000 US and Japanese organisations included in their survey, the expected benefits of ISO 14001 certification were not realised; in particular, expectations about market advantages were unrealistic. Hillary (2004) also noted that EMSs failed to fully meet the expectations of organisations. The analysis of prior European research reported that major issues associated with EMSs included the high costs and time required for certification and validation, and the lack of anticipated rewards such as expected cost savings. 
Although Melnyk, Sroufe and Calantone (2003) reported that EMS implementers gained some advantages over non-implementers, their study did not find that product quality improved and nor were wastes significantly reduced. Similarly, Andrews, Darnall and Gallagher (1999) reported some benefits, but also noted that not all the businesses gained a direct economic benefit from the implementation of an EMS. Prior research has also expressed concern that some EMSs do not require organisations to actually improve their environmental performance or necessarily seek verification for any environmental performance claims made by an organisation (Rondinelli and Vastag, 2000). Indeed Hertin et al. (2008) noted that improvement in environmental performance is seldom the primary motive behind implementation of an EMS and that the relationship between EMS implementation and environmental performance has not been thoroughly examined in the literature. Finally, it has been suggested that EMSs do not necessarily convert organisations towards improved environmentalism; rather, those organisations which are already focused on the environment will be more likely to voluntarily implement EMSs in the first place (Welch et al., 2003).

\section{EMSs IN THE WINE INDUSTRY}

In response to the increasing interest across the global wine industry in EMSs over the last decade, systems have been developed and promoted at both a regional and national level. For example, in California a Code of Sustainable Winegrowing Practices (the Code) was released in 2002 to wine companies in order to promote environmentally sound, economically feasible and socially equitable practices (Warner, 2007). The Code is a statewide initiative that focuses on ecological, economic and social practices from the 'ground to the bottle'. It focuses on topics such as soil, water and pest management, wine quality, energy efficiency, material handling, waste reduction, human resources, community and air quality (Broome and Warner, 2008). In Australia a number of regional EMS programmes have also been developed, including the Regional Environmental Best Practice for Viticulture project in the Victorian wine region, the Goulburn Valley Wine Association EMS project, and the Mount Lofty Watershed EMS project in South Australia (Tee et al., 2007). The South African wine industry has also developed and introduced a voluntary system to its members, entitled the Integrated Production of Wine scheme (Renton et al., 2002).

The New Zealand wine industry has also adopted an environmental focus in recent years. The CEO of New Zealand Winegrowers, the national industry association, believes that there is growing interest in the effects on the environment of the production, marketing and consumption of products amongst consumers, retailers and regulators (Gregan, 2007). Wines from New Zealand are often promoted on the basis of the clean and green image of the nation itself, so it is not surprising that the national industry association has set a target to have all wineries and grape growers acting in accordance with an independently audited environmental programme by vintage 2012 (Gabzdylova et al., 2009).

New Zealand Winegrowers introduced the Sustainable Winegrowing New Zealand (SWNZ) programme in 1998/1999. Since this time, the continually evolving SWNZ programme has been widely implemented by wineries and vineyards throughout the nation. Clayton and Stevens (2007) reviewed the New Zealand wine industry and described the SWNZ programme as "a self-audited, independently analysed, world-leading, environment management system for sustainable winery practices that assists growers, wineries and consumers" (pp. 73). SWNZ is based on a scorecard approach which provides targets or benchmarks with the aim of continually improving sustainability in both vineyards and 
wineries (Hughey et al., 2005). The SWNZ programme offers three tiers of participation, including a level at which accredited wineries are independently audited to ensure compliance to SWNZ protocols. The SWNZ programme was designed to: (a) provide a 'best practice' model of environmental practices; (b) provide quality assurance from vineyard to winery; (c) address consumer concerns; and (d) protect New Zealand's global wine export markets (Renton et al., 2002). Aside from SWNZ, wineries in New Zealand have also voluntarily implemented other formal environmental management systems including ISO 14001, BioGro, CarboNZero, Demeter and CertNZ. Informal in-house systems were not included in the scope of this study. Whilst pressure from regional or national industry associations might influence some wineries or vineyards to implement an EMS, there are several other factors which have been found to influence such a decision.

Several studies have examined the drivers for wineries implementing an EMS. A study of the US wine industry revealed that personal beliefs, corporate culture, regulatory and industry pressures, as well as the potential point of difference were the primary drivers of environmental stewardship (Marshall et al., 2005). Other drivers of proactive environmental behaviour amongst US wineries identified in the study included employee welfare, cost savings and wine quality. In the New Zealand wine industry, the most important drivers of proactive environmental behaviour were identified as environmental values, personal satisfaction, product quality and customers (Gabzdylova et al., 2009). Neither cost savings nor profits were found to be very important drivers to wineries when implementing an EMS.

Whilst the various drivers promote the implementation of EMSs in the global wine industry, studies have also noted the existence of factors which may limit EMS implementation by wineries. An Australian study reported that EMS implementation by small wine companies is inhibited by costs and the possibility that benefits may not arise (Tee et al., 2007). Similarly, New Zealand research suggested that disadvantages of EMSs are the costs involved with accreditation to a programme and the amount of paperwork involved (Hughey et al., 2005).

In addition to the previously mentioned benefits and costs to the organisation of implementing EMSs, several studies have pointed out that environmentally focused wineries can gain benefits in the marketplace. Warner (2007) suggested that wineries regard the implementation of a formal EMS as being an offensive strategy because consumers perceive a positive relationship between product quality and wines which are marketed as being environmentally friendly. Camilleri (2008) also noted that the Australian wine brand, Yalumba, consider their environmentally focused activities as an intrinsic aspect of wine quality. Analysis of consumer views regarding sustainable wines in the New Zealand market indicated that just over half of respondents thought that the use of environmentally sustainable wine production practices would result in no change in product quality, whilst almost 40 percent believed that quality would actually increase (Forbes et al., 2009). An earlier US study (Nowak and Washburn, 2002) revealed that consumer evaluations of wine quality did not increase if a winery implemented environmentally-focused business policies. However, the study did find that trust in the winery and brand equity significantly increased when a winery implemented pro-environmental business practices. Nowak and Washburn (2002) suggested that implementation of environmentally-focused practices by a winery may lead to product differentiation, competitive advantage and increased sales. Similarly, a case study of the Australian wine brand Banrock Station noted that its support of environmental conservation projects was a unique positioning strategy which differentiated its products, created a competitive advantage and increased its market share (Pugh and Fletcher, 2002). 
Research within the New Zealand wine industry has provided anecdotal evidence that wineries which have implemented the SWNZ system have not experienced marketing benefits as yet, perhaps due to a lack of eco-labelling to distinguish their products (Hughey et al., 2005). A similar study of Australian wineries also reported the marketing benefits typically associated with implementation of an EMS programme had proved to be elusive (Tee et al., 2007). Whilst some previous studies have determined that consumers would be willing to pay some level of premium for an environmentally friendly wine (Barber et al., 2009; Forbes et al., 2009; Loureiro, 2003), others have found no evidence that consumers are prepared to pay extra for a sustainably produced wine (Zoecklein, 2010). It is clear from the prior research that there is still much debate as to whether EMS implementation by wineries may result in any benefits in the marketplace or not. Whilst consumers do indicate a level of concern for the environment, this may not be matched by their actual purchasing behaviour.

Following analysis of the literature, the following research questions were developed:

1. Do New Zealand wineries which have implemented SWNZ consider this EMS to be sufficient in terms of monitoring and/or improving environmental performance?

2. Does the implementation of a single EMS or multiple EMSs in a winery result in improved environmental performance?

3. Does the implementation of a single EMS or multiple EMSs in a winery result in operational, social, economic or marketing benefits?

4. Does the implementation of multiple EMSs in a winery result in superior environmental performance when compared to that of wineries which have only implemented SWNZ?

\section{METHOD}

A questionnaire was used to examine the implementation of EMSs in New Zealand wineries. Questionnaires were used to enable the collection of a range of data at a time convenient to the respondent and at reasonable cost to the researchers across a population with wide geographical dispersion (Cavana et al., 2001). Further, while there is no commonly used and robust framework for evaluating environmental performance, most prior research has utilised postal or telephone surveys to gather self-reported assessments of perceived environmental performance and EMS effectiveness (Hertin et al., 2008).

The questionnaire was developed based on prior research examining environmental performance and environmental management systems (e.g. Gabzdylova et al., 2009; Melnyk et al., 2003; Oliver et al., 2008; Payraudeau and van der Werf, 2005) as well as information obtained from NZ Winegrowers about the SWNZ programme. The questionnaire consisted of a combination of categorical, likert scale, and open-ended questions (Brace, 2004) that enquired about the winery and its operations, the implementation of EMS at the winery, as well as the scope, benefits, and limitations of the EMS in operation. The items that were used to examine environmental performance can be viewed in the questionnaire in Appendix 1.

A pilot test of the questionnaire was undertaken with three local wineries and it was found that the questionnaire was readable understandable. Following completion of the pilot test the questionnaire was revised to ensure fuller coverage of the EMS. In particular, the questionnaire was modified to allow wineries to: (1) indicate that they had implemented an informal EMS and/or carboNZero; (2) provide more open-ended comments about the scope, benefits, and limitations of the EMS/s; (3) indicate the benefits of their EMS in relation to the disposal of organic winery waste; and (4) to clarify the reference to the use of glass in bottles. 
The population consisted of all New Zealand wineries with SWNZ accreditation as at December 2009 for which current contact details were obtainable. A total of 100 wineries, excluding the three pilot tested wineries, were included in the population. Due to the small population and the use of a questionnaire all wineries were included in the sample. The questionnaire was mailed in February 2010, along with a covering letter explaining the study and a pre-paid return envelope. Three weeks after the initial mail out a follow-up request was sent to all wineries by email. No incentive was given for completion of the questionnaire. Thirty eight usable questionnaires were returned, giving a response rate of 38 percent. The majority of responses were received within the initial three week period, with very few responses being received subsequent to the follow-up message. As a result, no tests for response bias between early and late responses were undertaken. While the questionnaire collected an extensive amount of data, only data relating to the research questions posed in this paper was selected for analysis.

Whilst respondent bias is an inherent issue with self-reported data, this study was not linked to any EMS accrediting organisation and thus the independence of the researchers should have helped to reduce bias. In addition, the sample was found to be representative of the New Zealand wine industry with both small and large wineries from all wine regions included.

\section{RESULTS AND DISCUSSION}

The first research question was to examine whether New Zealand wineries believed the SWNZ programme was sufficient as an EMS or if they needed to also implement additional EMSs. Tables 1 and 2 provide details of the number of EMSs implemented in each of the 38 wineries and the actual EMSs implemented by SWNZ accredited wineries in New Zealand (i.e. those in addition to SWNZ).

Table 1. Number of EMSs implemented in SWNZ accredited wineries

\begin{tabular}{lcc} 
& Number & Percent \\
\hline SWNZ only & 20 & 53 \\
SWNZ + one other EMS & 8 & 21 \\
SWNZ + two other EMSs & 9 & 24 \\
SWNZ + three other EMSs & 1 & 3 \\
\hline
\end{tabular}

Table 2. EMSs implemented in SWNZ accredited wineries

\begin{tabular}{lcc} 
Table 2. EMSs implemented in SWNZ accredited wineries & \\
\hline & Number & Percent \\
\hline Biogro & 12 & 32 \\
ISO 14001 & 9 & 24 \\
CarboNZero & 3 & 8 \\
Demeter & 1 & 3 \\
CertNZ & 1 & 3 \\
Other & 3 & 8 \\
\hline
\end{tabular}

It is somewhat surprising, given the domination of small producers in the New Zealand wine industry and prior research which has found that the high cost of EMS implementation and compliance is an inhibitor to wine companies (Hughey et al., 2005; Tee et al., 2007), that such a high number of wineries have invested in additional EMSs. This study also found indications that New Zealand wineries were concerned by the costs associated with EMSs, with twenty of the surveyed wineries (53 percent) stating that time and financial costs were both disadvantages associated with their EMSs. However, despite the costs, almost half of 
the responding SWNZ wineries had implemented at least one additional EMS. Furthermore, fourteen of the respondents (37 percent) stated they were currently working towards membership in another EMS. This result suggests that the SWNZ programme developed and promoted by New Zealand Winegrowers may not be seen as a sufficient EMS option for wineries and hence they are seeking additional environmental performance guidance elsewhere. Specifically, comments made by the respondents suggest that the SWNZ programme was not understood or widely recognised internationally and this was their primary reason for implementing additional EMSs to the SWNZ programme. If improvements were made to SWNZ, wineries may be able to address all their environmental issues through the use of a single EMS and therefore reduce the costs and time involved with implementing and maintaining accreditation in additional EMSs. A more comprehensive SWNZ programme could thus help to improve the financial viability of New Zealand wineries at what is a particularly difficult time for producers in the wine industry. This result gives a valuable insight into the implementation of multiple EMSs, an area that has seldom been explored in previous literature.

The second research question examined whether the implementation of a single EMS or multiple EMSs in a winery would result in improved environmental performance. Environmental performance was measured using a series of likert scaled items (ranging from 1-strongly agree to 5-strongly disagree). Analysis of the means assigned to the various items of environmental performance evaluated by the responding wineries indicated that environmental performance had improved across several areas, including reduced packaging waste, improved waste water disposal, improved management of cleaning product wastes, increased recycling of wastes, reduced materials sent to landfill and increased awareness of a winery's carbon footprint (see Table 3 below). This finding provides support for previous research suggesting that EMS implementation does improve environmental performance in organisations (e.g. Darnall et al., 2008; Potoski and Prakash, 2005; Stapleton et al., 2001). The wineries noted that one environmental aspect which did not improve with the implementation of an EMS or EMSs was that of increasing the use of energy generated from renewable sources. The costs of implementing alternative and renewable energy sources, such as wind or solar power, are high and are likely to be prohibitive to many smaller wine companies.

Table 3. The Effect of EMS/s on Environmental Performance in Wineries

\begin{tabular}{lc}
\hline Environmental Performance Item & Mean \\
\hline Resulted in few non-compliances with regional/district councils & 2.82 \\
Improved the disposal and management of organic winery waste & 2.26 \\
Increased the number and variety of native plants growing near the winery & 2.89 \\
Reduced the amount of packaging waste sent to landfills & 1.97 \\
Improved the quality of water in waterways near the winery & 2.53 \\
Improved waste water disposal methods & 2.18 \\
Reduced the amount of waste water to be disposed of & 2.47 \\
Improved management of cleaning products, including waste disposal & 2.11 \\
Resulted in a change in cleaning products used & 2.34 \\
Decreased the amount of cleaning products used & 2.42 \\
Decreased overall water use & 2.37 \\
Increased the level of waste material that is recycled & 2.03 \\
Increased the use of energy generated from renewable sources & 3.00 \\
Resulted in a change in the processing aids that are used & 2.68 \\
Decreased the amount of processing aids that are used & 2.92 \\
Decreased electricity use & 2.45 \\
Increased the level of waste material that is reused on site & 2.61 \\
Reduced the level of material sent to landfill & 2.16 \\
Reduced the thickness of glass in bottles & 2.47
\end{tabular}


The third research question sought to identify whether wineries which had implemented a single or multiple EMS were achieving operational, social, economic or marketing benefits. Overall, the responding wineries indicated that implementation of an EMS did not result in benefits such as increased access to international markets, increased sales in the domestic market, improved profitability, reduced overall costs, or improved wine quality. Four wineries (10 percent) did note in their comments that the morale and attitude of their staff had improved as a result of implementing an EMS, providing support for prior research (e.g. Andrews et al., 1999; Hillary, 2004). Our findings provide support for previous research which has suggested that EMS implementations do not result in any associated marketing benefits (Hughey et al., 2005; Tee et al., 2007; Welch et al., 2003). Prior research has also identified that wine quality is one of the important drivers for wineries implementing EMSs (Gabzdylova et al., 2009; Marshall et al., 2005), but our findings indicate that EMS implementation in wineries has not resulted in improved wine quality.

The final question examined whether the environmental performance of a winery would improve if they implemented more than a single EMS (i.e. one or more EMSs in addition to SWNZ). A series of Mann-Whitney tests were performed in order to compare the environmental performance of wineries which had only implemented SWNZ with wineries which had implemented additional EMSs. Overall, the environmental performance of wineries which had implemented multiple EMSs was found to be significantly better than the environmental performance of wineries which had solely implemented SWNZ. Wineries with additional EMSs indicated they had improved their environmental practices as a result of their EMSs and that these practices were continually improving due to their implemented EMSs. There were several environmental items which were rated significantly better by wineries with additional EMSs than by those with SWNZ only (significant items are shown in Table 4). Welch, Rana and Mori (2003) suggested that voluntary implementation of an EMS was more likely amongst those organisations which are already focused on the environment. Thus, it is also likely that wineries which implement multiple EMSs are more focused on their environmental impacts than those which only implement a single EMS and hence their environmental performance could be expected to be better.

Table 4. Performance of SWNZ-only Versus Multiple EMSs

\begin{tabular}{lccc}
\hline Environmental practices have improved as a result of EMS/s & $\begin{array}{c}\text { Mean Rank } \\
\text { SWNZ only }\end{array}$ & $\begin{array}{c}\text { Mean Rank } \\
\text { Mult. EMSs }\end{array}$ & Sig. \\
Environmental practices are continually improving & 25.00 & 15.50 & .002 \\
Our EMS/s has enhanced the reputation of our winery & 23.44 & 16.64 & .030 \\
Improved the disposal and mgmt of organic winery waste & 23.84 & 16.34 & .012 \\
Reduced the amount of packaging waste sent to landfills & 26.63 & 14.32 & .000 \\
Improved the quality of water in waterways near the winery & 23.25 & 16.77 & .046 \\
Improved waste water disposal methods & 23.75 & 16.41 & .034 \\
Reduced the amount of waste water to be disposed of & 23.56 & 16.55 & .022 \\
Improved mgmt of cleaning products, incl. waste disposal & 23.66 & 16.48 & .030 \\
Improved wine quality & 22.94 & 17.00 & .047 \\
Increased the level of waste material that is recycled & 23.00 & 16.95 & .049 \\
Decreased electricity use & 22.94 & 17.00 & .042 \\
Reduced the thickness of glass in bottles & 24.56 & 15.82 & .009 \\
Raised awareness of our carbon footprint & 23.56 & 16.55 & .042 \\
\hline
\end{tabular}




\section{CONCLUSIONS}

This paper has added to current knowledge regarding the implementation of an EMS and resulting environmental, social and economic benefits. The findings indicate that environmental performance is improved, across a number of areas, in wineries which have implemented a single EMS or multiple EMSs. This result provides support for the idea that implementation of an EMS or EMSs is achieving the basic aim of improved environmental performance in accredited organisations. As noted by Gregan (2007) the growing environmental interest amongst consumers, retailers and regulators means that wine producers must focus on improving their environmental performance, and our findings suggest that EMS implementation can help to achieve this.

However, this study has found little evidence that EMS implementation has resulted in any non-environmental benefits. Of particular concern, wineries did not gain tangible marketing and economic benefits such as increased access to international markets, increased sales in domestic markets, improved profitability or reduced costs. As more and more global wine producers incorporate some level of environmental focus into their organisations, any possible point of difference or competitive advantage is likely to be negated. The reasons why EMS implementation has not resulted in marketing and economic benefits for wineries were not assessed in this paper and are a valid topic for future research.

In addressing a gap in prior research, this paper has examined whether environmental performance is better when multiple EMSs are implemented in an organisation compared with a single implemented EMS (i.e. SWNZ). The results indicate that implementing multiple EMSs can lead to significantly better environmental performance. However, the results have limited generalisability due to the small sample size and focus on wineries in New Zealand. Further research would be required to see if this result would be generalisable across other industries and wineries in other nations.

At a practical level, our findings have identified areas where wineries believed the SWNZ programme was insufficiently helping them to improve environmental performance. These identified environmental areas provide information on the components of the SWNZ programme which could be re-examined from an effectiveness point of view. This information should be of value to New Zealand Winegrowers as they continue to develop and improve the comprehensiveness of the SWNZ programme.

Despite the costs associated with EMSs and the limited proven non-environmental benefits, including marketing benefits, New Zealand wineries appear to be keen to implement formal programmes which assist them to improve their environmental performance. The utilisation of various EMSs amongst New Zealand wineries suggests that, as yet, no single EMS is considered sufficiently effective.

\section{Acknowledgements}

The authors wish to thank Dr Michaela Balzarova and Anne Spicer who both contributed to the study and the financial contribution from Lincoln University's Research Fund.

\section{REFERENCES}


Andrews, R. N. L., Darnall, N., and Gallagher, D. R (1999), “Environmental management systems: A sustainable strategy for a sustainable world?”, in Sustainability: Ways of Knowling, Ways of Acting: Proceedings of the Eighth International Conference of the Greening of Industry Network, Kenan-Flagler Business School, 14-17 November.

Barber, N., Taylor, C. and Strick, S. (2009), "Wine consumers' environmental knowledge and attitudes: Influence on willingness to purchase”, International Journal of Wine Research, Vol. 1, pp. 59-72.

Barla, P. (2007), “ISO 14001 certification and environmental performance in Quebec's pulp and paper industry”, Journal of Environmental Economics and Management, Vol. 53 No. 3, pp. 291-306.

Boiral, O. (2007), “Corporate greening through ISO 14001: A rational myth?”, Organization Science, Vol. 18 No. 1, pp. 127-146.

Brace, I. (2004), Questionnaire design, Kogan Page Limited, London.

Broome, J. C. and Warner, K. D. (2008), “Agro-environmental partnerships facilitate sustainable wine-grape production and assessment”, available at http://CaliforniaAgriculture.ucop.edu

Camilleri, C. S. (2008), “Sharing Yalumba: Communicating Yalumba's commitment to sustainable winemaking”, Corporate Communications, Vol. 13 No. 1, pp. 18-41.

Cavana, R. Y., Delahaye, B. L., and Sekaran, U. (2001), Applied business research: Qualitative and quantitative methods, John Wiley \& Sons, Queensland, Australia. Clayton, G. and Stevens, N. (2007), “False idol economy: The New Zealand wine industry”, International Journal of Systems Applications, Engineering \& Development, Vol. 3 No. 1, pp. 69-74.

Darnall, N., Jolley, G. J., and Handfield, R. (2008), “Environmental management systems and green supply chain management: Complements for sustainability?”, Business Strategy and the Environment, Vol, 18, pp. 30-45.

Forbes, S. L., Cohen, D. A., Cullen, R., Wratten, S. D., and Fountain, J. (2009), “Consumer attitudes regarding environmentally sustainable wine: An exploratory study of the New Zealand marketplace”, Journal of Cleaner Production, Vol. 17 No. 13, pp. 11951199. 
Gabzdylova, B., Raffensperger, J. F., and Castka, P. (2009), "Sustainability in the New Zealand wine industry: drivers, stakeholders and practices”, Journal of Cleaner Production, Vol. 17 No. 11, pp. 992-998.

Gregan, P. (2007), “Sustainability Pt II: The path forward”, New Zealand Wine Grower, Vol. 10 No. 5, pp. 5.

Hertin, J., Berkhout, F., Wagner, M., and Tyteca, D. (2008), “Are EMS environmentally effective? The link between environmental management systems and environmental performance in European companies”, Journal of Environmental Planning and Management, Vol. 51 No. 2, pp. 259-283.

Hillary, R. (2004), “Environmental management systems and the smaller enterprise”, Journal of Cleaner Production, Vol. 12, pp. 561-569.

Hughey, K. F. D., Tait, S. V., and O'Connell, M. J. (2005), “Qualitative evaluation of three environmental management systems in the New Zealand wine industry”, Journal of Cleaner Production, Vol. 13, pp. 1175-1187.

Loureiro, M. L. (2003), "Rethinking new wines: Implications of local and environmentally friently labels”, Food Policy, Vol. 28, pp. 547-560.

Marshall R., Cordano, M. and Silverman, M. (2005), “Exploring individual and institutional drivers of proactive environmentalism in the US wine industry”, Business Strategy and the Environment, Vol. 14, pp. 92-109.

Melnyk, S. A., Sroufe, R. P., and Calantone, R. (2003), “Assessing the impact of environmental management systems on corporate and environmental performance”, Journal of Operations Management, Vol. 21 No. 3, pp. 329-351.

Musee, N., Lorenzen, L., and Aldrich, C. (2007), “Cellar waste minimization in the wine industry: A systems approach”, Journal of Cleaner Production, Vol. 15, pp. 417-431.

Nawrocka, D. and Parker, T. (2009), “Finding the connection: Environmental management systems and environmental performance”, Journal of Cleaner Production, Vol. 17 No. 1, pp. 601-607.

Nowak, L. I. and Washburn, J. H. (2002), “Building brand equity: Consumer reactions to proactive environmental policies by the winery”, International Journal of Wine Marketing, Vol. 14 No. 3, pp. 5-19. 
Oliver, P., Rodríguez, R., and Udaquiola, S. (2008), "Water use optimization in batch process industries. Part 1: design of the water network”, Journal of Cleaner Production, Vol. 16 No. 12, pp. 1275-1286.

Payraudeau, S., and van der Werf, H. M. G. (2005), "Environmental impact assessment for a farming region: a review of methods”, Agriculture, Ecosystems \& Environment, Vol. 107 No. 1, pp. 1-19.

Potoski, M., and Prakash, A. (2005), “Covenants with weak swords: ISO 14001 and facilities' environmental performance”, Journal of Policy Analysis and Management, Vol. 24 No. 4, pp. 745-769.

Pugh, M. and Fletcher R. (2002), “Green international wine marketing”, Australasian Marketing Journal, Vol. 10 No. 3, pp. 76-85.

Renton, T., Manktelow, D., and Kingston, C. (2002), "Sustainable winegrowing: New Zealand's place in the world", in Proceedings of the Romeo Bragato Conference,

Christchurch, September 2002. Christchurch, New Zealand: New Zealand Winegrowers.

Rondinelli, D. A., and Vastag, G. (2000), "Panacea, common sense, or just a label? The value of ISO 14001 environmental management systems”, European Management Journal, Vol. 18, pp. 499-511.

Ruggieri, L., Cadena, E., Martinez-Blanco, J., Gasol, C. M., Rieradevall, J., Gabarrell, X., Gea, T., Sort, X., and Sanchez, A. (2009), "Recovery of organic wastes in the Spanish wine industry: Technical, economic and environmental analyses of the composting process”, Journal of Cleaner Production, Vol. 17, pp. 830-838.

Stapleton, P., Glover M., and Davis, S. (2001), Environmental management systems: An implementation guide for small and medium sized organizations, NSF International, Ann Arbor, MI.

Tee, E., Boland, A-M., and Medhurst, A. (2007), "Voluntary adoption of Environmental Management Systems in the Australian wine and grape industry depends on understanding stakeholder objectives and drivers”, Australian Journal of Experimental Agriculture, Vol. 47, pp. 273-283.

Warner, K. D. (2007), “The quality of sustainability: Agroecological partnerships and the geographic branding of California winegrapes”, Journal of Rural Studies, Vol. 23, pp. 142-155.

Welch, E. W., Rana, A., and Mori, Y. (2003), “The promises and pitfalls of ISO 14001 for competitiveness and sustainability: A comparison of Japan and the United States", Green Management International, Vol. 44, pp. 59-73.

Zoecklein, B. (2010), "Defining sustainability: What does it really mean for the wine industry?”, Vineyard and Winery Management, Vol. Jan-Feb, pp. 104-109. 


\section{Appendix 1 - Questionnaire}

Section One: Winery Background (not included in this appendix)

Section Two: Environmental Management Systems in Operation at the Winery (not included in this appendix)

\section{Section Three: Environmental Management System(s)}

\begin{tabular}{|c|c|c|c|c|c|c|}
\hline Based on your experience of your environmental management system/s: & 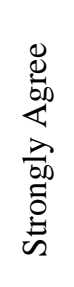 & 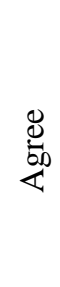 & 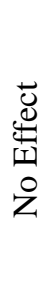 & 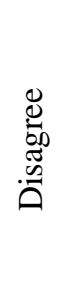 & 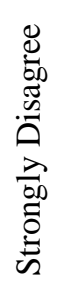 & 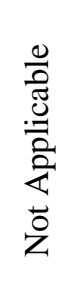 \\
\hline $\begin{array}{l}\text { 10. Our environmental management system covers all of the critical } \\
\text { environmental areas }\end{array}$ & 1 & 2 & 3 & 4 & 5 & 6 \\
\hline $\begin{array}{l}\text { 11. Our environmental management system is preventing long-term harm } \\
\text { to the environment caused by our winery }\end{array}$ & 1 & 2 & 3 & 4 & 5 & 6 \\
\hline $\begin{array}{l}\text { 12. Environmental practices in this winery have improved as a result of our } \\
\text { environmental management system(s) }\end{array}$ & 1 & 2 & 3 & 4 & 5 & 6 \\
\hline $\begin{array}{l}\text { 13. Our environmental management system has had benefits that have } \\
\text { definitely outweighed any costs incurred }\end{array}$ & 1 & 2 & 3 & 4 & 5 & 6 \\
\hline $\begin{array}{l}\text { 14. Having an environmental management system in operation has opened } \\
\text { up/maintained access to more international markets and retailers }\end{array}$ & 1 & 2 & 3 & 4 & 5 & 6 \\
\hline $\begin{array}{l}\text { 15. Sales of our wine in New Zealand have increased as a result of our } \\
\text { adoption of an environmental management system(s) }\end{array}$ & 1 & 2 & 3 & 4 & 5 & 6 \\
\hline $\begin{array}{l}\text { 16. Profitability in our winery has improved because of cost savings } \\
\text { resulting from our environmental management system }\end{array}$ & 1 & 2 & 3 & 4 & 5 & 6 \\
\hline $\begin{array}{l}\text { 17. Through our environmental management system(s), we employ the best } \\
\text { practices relevant to the wine industry. }\end{array}$ & 1 & 2 & 3 & 4 & 5 & 6 \\
\hline $\begin{array}{l}\text { 18. Environmental practices at our winery are continually improving due to } \\
\text { the environmental management system(s) that we use }\end{array}$ & 1 & 2 & 3 & 4 & 5 & 6 \\
\hline $\begin{array}{l}\text { 19. Our winery is provided with information relating to new technologies } \\
\text { and practices that we can build into our environmental management } \\
\text { system(s) }\end{array}$ & 1 & 2 & 3 & 4 & 5 & 6 \\
\hline $\begin{array}{l}\text { 20. I would recommend the environmental system(s) that we use to other } \\
\text { wineries }\end{array}$ & 1 & 2 & 3 & 4 & 5 & 6 \\
\hline
\end{tabular}

Section Four: Results of Using Environmental Management System(s) in the Winery

\begin{tabular}{|c|c|c|c|c|c|c|}
\hline Using our environmental management system/s in our winery has: & 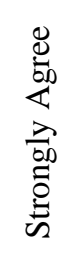 & 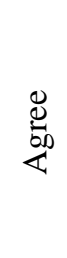 & 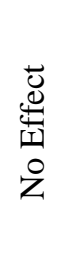 & 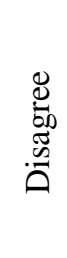 & 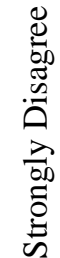 & 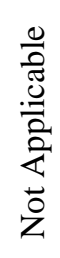 \\
\hline
\end{tabular}




\begin{tabular}{|c|c|c|c|c|c|c|}
\hline $\begin{array}{l}\text { 21. Resulted in fewer non-compliances with Regional/District Council } \\
\text { regulations and/or Resource Management Act consent requirements }\end{array}$ & 1 & 2 & 3 & 4 & 5 & 6 \\
\hline 22. Enhanced the reputation of our winery & 1 & 2 & 3 & 4 & 5 & 6 \\
\hline $\begin{array}{l}\text { 23. Improved the disposal and management of organic winery waste (i.e. } \\
\text { stems, marc or grape pressings) }\end{array}$ & 1 & 2 & 3 & 4 & 5 & 6 \\
\hline $\begin{array}{l}\text { 24. Increased the number and variety of native plants growing near the } \\
\text { winery }\end{array}$ & 1 & 2 & 3 & 4 & 5 & 6 \\
\hline 25. Reduced the amount of packaging waste sent to landfill & 1 & 2 & 3 & 4 & 5 & 6 \\
\hline $\begin{array}{l}\text { 26. Improved the quality of water in waterways in the locality of the } \\
\text { winery }\end{array}$ & 1 & 2 & 3 & 4 & 5 & 6 \\
\hline 27. Improved the working environment for employees & 1 & 2 & 3 & 4 & 5 & 6 \\
\hline 28. Improved waste water disposal methods & 1 & 2 & 3 & 4 & 5 & 6 \\
\hline 29. Reduced the amount of waste water to be disposed of & 1 & 2 & 3 & 4 & 5 & 6 \\
\hline $\begin{array}{l}\text { 30. Improved management of cleaning products including disposal of } \\
\text { waste }\end{array}$ & 1 & 2 & 3 & 4 & 5 & 6 \\
\hline 31. Resulted in a change in cleaning products used & 1 & 2 & 3 & 4 & 5 & 6 \\
\hline 32. Decreased the amount of cleaning products used & 1 & 2 & 3 & 4 & 5 & 6 \\
\hline 33. Reduced overall costs & 1 & 2 & 3 & 4 & 5 & 6 \\
\hline 34. Decreased overall water use & 1 & 2 & 3 & 4 & 5 & 6 \\
\hline 35. Improved wine quality & 1 & 2 & 3 & 4 & 5 & 6 \\
\hline 36. Increased the level of waste material that is recycled & 1 & 2 & 3 & 4 & 5 & 6 \\
\hline $\begin{array}{l}\text { 37. Increased the use of energy generated from renewable sources from the } \\
\text { winery }\end{array}$ & 1 & 2 & 3 & 4 & 5 & 6 \\
\hline $\begin{array}{l}\text { 38. Resulted in a change in the processing aids that are used e.g. fining } \\
\text { agents }\end{array}$ & 1 & 2 & 3 & 4 & 5 & 6 \\
\hline 39. Decreased the amount of processing aids that are used & 1 & 2 & 3 & 4 & 5 & 6 \\
\hline 40. Decreased electricity use & 1 & 2 & 3 & 4 & 5 & 6 \\
\hline 41. Increased the level of waste material that is reused on site & 1 & 2 & 3 & 4 & 5 & 6 \\
\hline 42. Reduced the level of material sent to landfill & 1 & 2 & 3 & 4 & 5 & 6 \\
\hline 43. Reduced the thickness of glass in bottles & 1 & 2 & 3 & 4 & 5 & 6 \\
\hline 44. Raised our awareness of our carbon & 1 & 2 & 3 & 4 & 5 & 6 \\
\hline
\end{tabular}

45. Do you consider that the changes you have indicated in the table above have resulted directly from your participation in SWNZ or have they occurred because of other environmental management system(s) you have implemented?

46. Are there other benefits from using your environmental management system(s)?

47. Are there disadvantages associated with using your environmental management system(s)?

48. Can you identify any practices in your winery that you consider are still in need of environmental improvement?

49. Do you have any further comments on the issues raised in this survey, or on the survey itself? 